\title{
AVALIAÇÃO DA ADAPTAÇÃO DOCENTE AO ENSINO REMOTO EMERGENCIAL
}

Arthur Lima de Almeida ${ }^{1}$

Rodrigo de Cássio da Silva ${ }^{2}$

\section{RESUMO}

A pandemia da Covid-19 trouxe inúmeros desafios para a sociedade, sobretudo, no que se refere ao novo formato do processo de ensino e aprendizagem, e é neste cenário em que se insere a presente pesquisa. Visando compreender e avaliar de que maneira os docentes estavam se adaptando, um questionário estruturado foi enviado a professores do Brasil, por meio das redes sociais e contatos pessoais, o que possibilitou a obtenção de 419 respostas de profissionais das mais diversas regiões do país. Com perfis diversos e nível de atuação também, a maioria dos participantes questionados atua no ensino superior e no ensino fundamental II. Tal pesquisa nos permitiu realizar diversas conclusões, sendo uma delas que grande parte dos docentes se sente sobrecarregada com o novo formato de ensino, cerca de $78 \%$, e que a falta de equipamentos e de locais adequados é o principal problema apresentado no período atual. Apesar disso, eles buscam, por conta própria, outras ferramentas que possam servir de apoio ao ensino remoto. Este trabalho destacou a necessidade de uma formação continuada de qualidade para todos os professores, bem como serviu de alerta à comunidade acadêmica sobre a sobrecarga de trabalho dos mesmos, situação já discutida em pesquisas diversas, acentuada, porém, nesta investigação, devido ao contexto pandêmico.

Palavras-chave: Covid-19. Ensino. Formação docente. Educação a distância. Tecnologias educacionais.

\section{EVALUATION OF FACULTY ADAPTATION TO EMERGENCY REMOTE TEACHING}

\begin{abstract}
The COVID-19 pandemic has brought numerous challenges to society, especially regarding the new format of the teaching and learning process and this is the context of the present research. Aiming to understand and evaluate how teachers were adapting, a structured questionnaire was sent to teachers in Brazil, through social networks and personal contacts,

${ }^{1}$ Graduando em Licenciatura em História no Centro Universitário Internacional - UNINTER. E-mail: 2841046@ alunouninter.com

${ }^{2}$ Doutor e Mestre em Ciências Biológicas pela Universidade Federal do Rio de Janeiro e pelo Instituto de Biofísica Carlos Chagas Filho. E-mail: rodrigosilva2005@yahoo.com.br
\end{abstract}


which made it possible to obtain 419 responses from professionals in several regions of the country. With diverse profiles, and level of activity as well, most of the teachers questioned work in Higher Education and in Middle School. This research allowed us to reach several conclusions, one of them being that most teachers feel overloaded with the new teaching format, about $78 \%$, and that the lack of equipment and adequate places are the main problems presented in this period. Despite this, these professionals are looking (on their own) for other tools to support remote teaching. This research highlighted the need for quality continuing education for all teachers, it also served as an alert to the academic community about the overload of teachers' work, a situation that has already been discussed in various researches, but is accentuated in this study due to the pandemic context.

Keywords: Covid-19; Teaching. Teacher Training. Distance Learning. Educational Technologies.

\section{EVALUACIÓN DE LA ADAPTACIÓN DEL PROFESORADO A LA ENSEÑANZA A DISTANCIA DE EMERGENCIA}

\section{RESUMEN}

La pandemia de COVID-19 ha supuesto muchos desafíos a la sociedad, especialmente en lo que respecta al nuevo formato del proceso de enseñanza y aprendizaje. En este contexto se inserta la presente investigación. Con el objetivo de comprender y evaluar la adaptación de los profesores, se envió un cuestionario estructurado a los profesores de Brasil, a través de las redes sociales y los contactos personales. Se obtuvieron un total de 419 respuestas de profesores de diferentes regiones del país. Con perfiles diversos, y nivel de actividad también, la mayoría de los profesores encuestados trabajan en la Enseñanza Superior y en Primaria II. Esta investigación nos permitió sacar varias conclusiones, una de ellas es que la mayoría de los profesores se sienten sobrecargados con el nuevo formato de enseñanza, alrededor del 78\%, y que la falta de equipamiento y de plazas adecuadas son los principales problemas que se presentan en este periodo. A pesar de ello, estos profesionales buscan (por su cuenta) otras herramientas que puedan servir de apoyo a la enseñanza a distancia. En esta investigación se puede destacar la necesidad de una formación continua de calidad para todos los profesores. Este trabajo sirve para alertar a la comunidad académica sobre la sobrecarga de trabajo de los profesores, una vez ya denunciada en varias investigaciones, sin embargo, esta investigación pretende alertar en el contexto de la pandemia.

Palabras clave: COVID-19. Enseñanza. Formación del profesorado. Educación a distancia. Tecnologías educativas. 


\section{INTRODUÇÃO}

Esta pesquisa foi motivada devido às situações vivenciadas pelos autores com relação às constantes reivindicações de docentes ao novo formato de ensino ao qual a maior parte teve que se adaptar em função do isolamento social provocado pela pandemia da Covid-19 (OMS, 2020). Portanto, é neste contexto em que esta investigação se insere.

Para Saraiva, Traversini e Lockmann (2020), as principais consequências negativas do chamado "novo normal" no que se refere ao processo educativo se debruçam, principalmente, quando isso está relacionado à intensificação do trabalho docente. Adicionalmente, a válida preocupação com o aprendizado dos estudantes, por não ter sido transposta da mesma medida para o trabalho docente que, à sua maneira, teve que se adaptar a essa nova condição de trabalho. Assim, as questões pedagógicas, disciplinares e avaliativas talvez não estejam a contento, se comparadas ao exercício da atividade presencial.

Posto isso, embora haja certo consenso entre os especialistas acerca da pouca eficácia da substituição do ensino presencial pelo remoto, este poderá contribuir para minimizar eventuais danos causados pela paralisação das atividades escolares. (SAIBA, 2020).

O que justificaria tal ação está pautado em relatórios emitidos pelo Banco Mundial, o qual apontou que, aproximadamente, 1,4 bilhão de estudantes estavam fora da sala de aula em mais de 150 países (WOLD BANK GROUP, 2020). Mas, quando se trata, especificamente, de América Latina, esse número representa $95 \%$ dos alunos matriculados, de acordo com o Fundo das Nações Unidas para a Infância (UNICEF, 2020).

No Brasil, foi publicada a Portaria $n^{\circ} 343$, de 17 de março de 2020, que dispõe sobre a substituição das aulas presenciais por aulas em meios digitais enquanto durar a situação de pandemia do novo coronavírus - Covid-19 (BRASIL, 2020).

No mesmo documento, fica explícito, ainda, em seu art. $1^{\circ}$ :

Art. $1^{\circ}$ Autorizar, em caráter excepcional, a substituição das disciplinas presenciais, em andamento, por aulas que utilizem meios e tecnologias de informação e comunicação, nos limites estabelecidos pela legislação em vigor, por instituição de educação superior integrante do sistema federal de ensino, de que trata o art. $2^{\circ}$ do Decreto $n^{\circ} 9.235$, de 15 de dezembro de 2017. (BRASIL, 2020).

Portanto, devido ao distanciamento social imposto pela referida situação, foi necessária uma adequação nos processos de ensino e aprendizagem em todos os seus níveis. Nesse contexto, as Tecnologias Digitais da Informação e Comunicação (TDICs) e a internet passaram a exercer papel fundamental na vida tanto do educador quanto do educando, visando suprir a ausência nas salas de aulas. (GOMES et al., 2020). 
Evidencia-se, então, que, mesmo em um período pandêmico:

É preciso continuar entregando conteúdos aos alunos, encontrar meios para manter um diálogo rico e vencer um grande desafio: manter a qualidade do processo de ensino-aprendizagem considerando todas as novidades e limitações desse período, em que ser criativo e utilizar as tecnologias digitais, como aplicativos e plataformas, são tão necessários à prática docente. (ALMEIDA et al., 2021, p. 74).

No entanto, Saviani e Galvão (2021, p. 38) afirmam que:

Mesmo para funcionar como substituto, excepcional, transitório, emergencial, temporário etc., em que pesem as discordâncias que temos com o ensino não presencial e que iremos abordar, determinadas condições primárias precisariam ser preenchidas para colocar em prática o "ensino" remoto, tais como o acesso ao ambiente virtual propiciado por equipamentos adequados (e não apenas celulares); acesso à internet de qualidade; que todos estejam devidamente familiarizados com as tecnologias e, no caso de docentes, também preparados para o uso pedagógico de ferramentas virtuais.

Diante do cenário atual, muitas pesquisas acerca do papel docente no enfrentamento desse novo desafio têm sido desenvolvidas. Adicionalmente, a maior parte delas permeia as diferentes estratégias e práticas pedagógicas utilizadas pelos professores, suas ferramentas de interação, as plataformas de aprendizagem e os novos paradigmas a serem enfrentados. Contudo, poucas exploram a adaptação desses profissionais a esse novo "normal". Nesse sentido, o principal objetivo deste estudo é avaliar o grau de adaptação de docentes no tocante ao Ensino Remoto Emergencial (ERE), sob o contexto de satisfação pessoal, treinamentos no uso de plataformas e ferramentas digitais, bem como a sobrecarga de trabalho e, mediante isso, propor meios para superar a situação sem perder, ou pelo menos amenizar, a qualidade do ensino ofertado.

\section{METODOLOGIA}

Para a presente pesquisa quali-quantitativa, a coleta dos dados foi realizada por meio de um questionário estruturado (utilizando a plataforma do Google Forms) que continha 18 perguntas fechadas. Estão, entre as perguntas, informações como: região, tempo de atuação como docente, nível e modalidade de ensino em que atua durante a pandemia, ou em que atuou antes dela, questões sobre ferramentas digitais para o ensino remoto, autoavaliação de adaptação, formação docente, entre outras. O período de coleta de informações foi de 10/08/2020 a 17/08/2020.

A divulgação do instrumento da pesquisa se deu por meio de contatos pessoais (WhatsApp e e-mail)e de redes sociais (Facebook), totalizando 419 professores participantes, atuantes de diversos níveis de ensino desde a educação básica até o ensino superior, aos quais foi solicitado que disseminassem em suas redes de contato o formulário com as 
perguntas, a fim de que houvesse um maior número de participantes. Com o questionário, estava o objetivo da pesquisa que, certamente, incentivou a participação e a colaboração dos docentes mediante suas experiências.

Além disso, foi realizada uma análise interpretativa, que, segundo Severino (2007, p. 56), é a parte complicada da pesquisa, "uma vez que os riscos de interferência da subjetividade do leitor são maiores, além de pressupor outros instrumentos culturais e formação específica".

\section{RESULTADOS E DISCUSSÃO}

Foram questionados 419 professores de diferentes regiões do país, dos quais, apenas dois decidiram por não responder (Gráfico 1).

\section{Gráfico 1 - Estados e suas representatividades docentes com relação à presente pesquisa.}

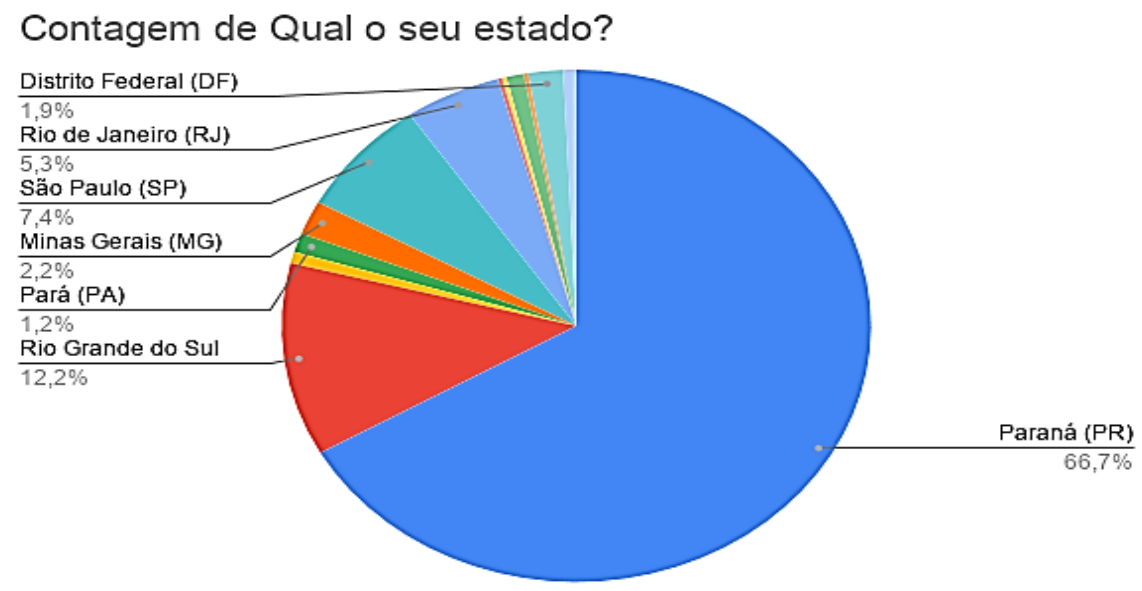

Fonte: Elaborado pelos autores (2020).

A maioria dos docentes pesquisados era do estado do Paraná, seguido pelo Rio Grande do Sul, São Paulo e Rio de Janeiro, com idade variando entre 18 e mais de 60 anos. A maior parte atua, ainda, na educação superior (graduação), ensino fundamental II e pós-graduação (Gráfico 2). Na ocasião, os docentes poderiam marcar mais de uma opção caso atuassem em mais de um nível de ensino. O número de docentes atuantes na educação pública e privada se mostrou bastante semelhante (221 e 226 professores, respectivamente). 
Gráfico 2 - Nível de ensino onde atuam os docentes pesquisados.

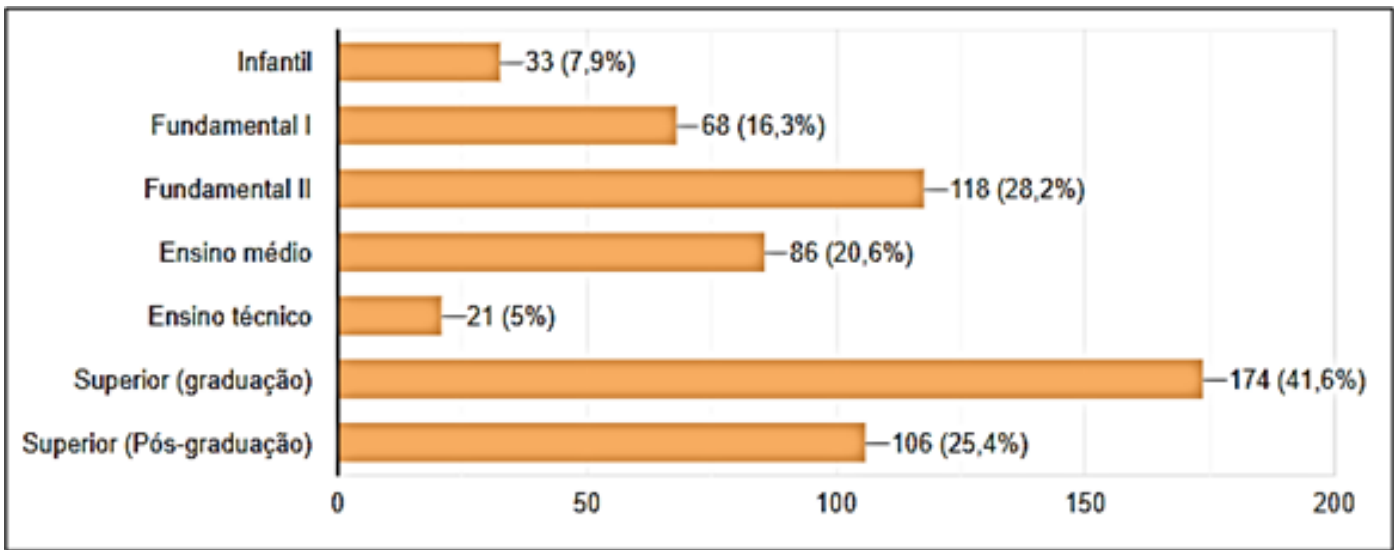

Fonte: Elaborado pelos autores (2020).

A maior parte dos docentes pesquisados informou que, antes da pandemia, atuava na modalidade presencial, isto é, $86,8 \%$, ao passo que os demais já atuavam na modalidade a distância, no ensino híbrido ou em outra modalidade.

O presente estudo demonstrou que a maioria dos docentes pesquisados $(78 \%)$ se sente sobrecarregada em relação à modalidade que atendia anteriormente (Gráfico 3). Além do mais, outras duas dificuldades apresentadas pelos docentes se referem à falta de equipamentos e de local adequado para ministrarem suas aulas $(37,3 \%)$, bem como às inexperiências em atividades de ensino a distância $(35,2 \%)$.

Gráfico 3 - Percentual docente em resposta ao questionamento sobre estarem se sentindo mais sobrecarregados em relação à modalidade na qual atuavam antes da pandemia.
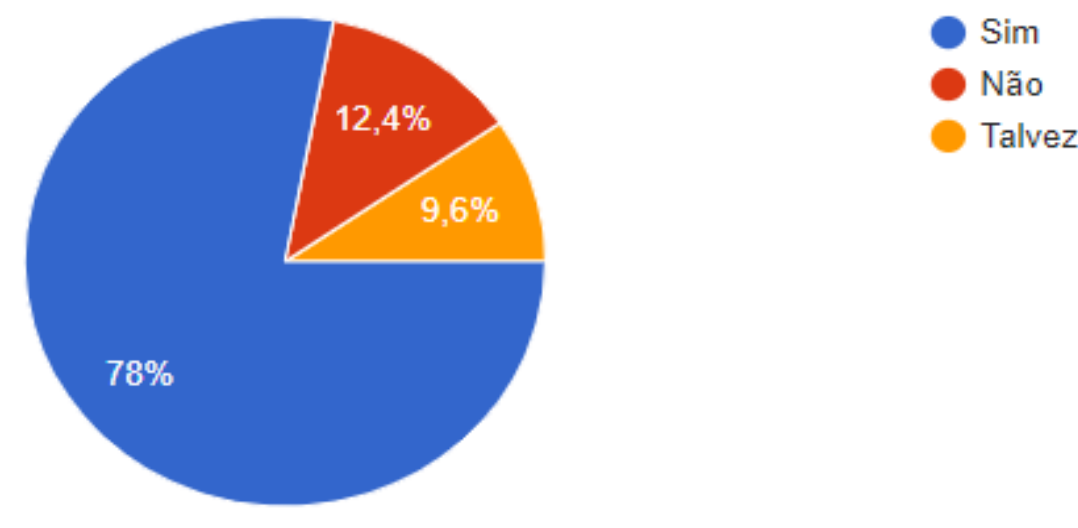

Fonte: Elaborado pelos autores (2020).

Esse fato já havia sido observado em estudo conduzido por Saraiva, Traversini e Lockmann (2020), em que os pesquisadores avaliaram entrevistas em diferentes veículos 
de comunicação que tratavam dessa temática. Ainda para os autores supracitados, essa modalidade de trabalho, caracterizada por regimes exaustivos de trabalho e que é bem dissociada do planejamento de execução dessas atividades educativas e pedagógicas, foi denominada de educação delivery.

Estudos demonstram que há, de fato, um esgotamento tanto físico quanto emocional de estudantes e professores no contexto das aulas remotas, durante o período da pandemia da Covid-19 (CAMÊLO, 2021; CONSETINO, 2021; ALVES; FARIAS, 2020).

A definição de estresse, de acordo com a Mental Health Foundation, "é a sensação de estar sobrecarregado ou de ser incapaz de lidar com a pressão mental ou emocional" e pode levar a mudanças de comportamento como, por exemplo, diminuição na vontade de aprender e ensinar, faltas frequentes, irritação, frustração e diminuição de responsabilidade. (MENTAL HEALTH FOUNDATION, 2021; NURHIDAYATI et al., 2021).

Desse modo, situações como essas podem levar a distúrbios neuropsíquicos, como depressão, ansiedade e, principalmente, Síndrome de Burnout. Em professores, a Síndrome de Burnout já é uma condição bem estabelecida e extensamente estudada justamente pelo intenso desgaste físico e emocional que causa nesses trabalhadores. (BROUWERS; TOMIC; BOLUIJT, 2011; DALCIN; CARLOTTO, 2017; VAEZI; FALLAH, 2011; DIEHL; CARLOTTO, 2020).

É caracterizada como uma doença que acomete trabalhadores expostos de forma sistematicamente prolongada ao estresse laboral, exigindo maior esforço psicológico, demonstrando esgotamento físico e mental. (VAEZI; FALLAH, 2011).

Destaca-se aqui que, embora esse dado não tenha sido coletado na presente pesquisa, as mulheres que, por muitas vezes, atuam em dupla ou tripla função (mães, docentes e donas de casa) foram as mais atingidas (JASKIW; LOPES, 2021), o que, com efeito, corrobora ainda mais o sentimento de sobrecarga relatado pelos respondentes.

Outra importante conclusão se refere à maioria dos docentes questionados $(46,4 \%)$, os quais não foram orientados quanto ao uso de ferramentas tecnológicas adicionais no ensino remoto. Compreender a necessidade docente, assim como suas deficiências, é fundamental para que haja um adequado processo de formação continuada desses profissionais.

Segundo Libâneo (2001, p.10), é preciso uma formação "que o auxilie a ajustar sua didática às novas realidades da sociedade, do conhecimento, do aluno, dos diversos universos culturais". Nesse caso, notadamente, não houve esse tipo de formação para a maior parte dos entrevistados o que, certamente, influenciará na qualidade do material apresentado e, portanto, resultará em uma baixa eficiência no processo de ensino e aprendizagem. Mesmo por estar em um contexto pandêmico, a realização de momentos de trocas de experiências, por meio de grupos colaborativos, por exemplo, seria de grande 
valia para o aperfeiçoamento da prática pedagógica. Tais encontros podem ser realizados com recursos já conhecidos, como as plataformas de reuniões on-line.

Para Kraviski (2019, p. 21) diz que:

Professores precisam formar-se para formar. Formar professores em serviço oriundos de outra geração para atuação no contexto atual evidencia-se como uma das problemáticas para a equipe de gestores em cursos de licenciatura na educação superior. Esse cenário ainda é repleto das tendências educacionais, que se configuram com a incorporação de novas roupagens para as temáticas de necessidade constante de inovação nas práticas pedagógicas, com discursos de ambientes enriquecidos com tecnologias.

Nesse sentido, além da formação docente deficitária, correspondente a $51,2 \%$, foi verificado que a formação continuada para atuação nesta fase emergencial também o foi.

Essa questão se reflete na percepção dos professores no que diz respeito à adaptação do próprio aluno à sua maneira de trabalhar na nova modalidade, na medida em que, quando foram perguntados se achavam que os alunos haviam se adaptado às suas formas de trabalhar no ensino remoto, a maioria respondeu "talvez" (Gráfico 4).

Gráfico 4 - Percepção docente sobre a adaptação dos alunos com relação à sua forma de trabalhar. Foi perguntado: "Você acha que os estudantes têm se adaptado à sua maneira de trabalhar no ensino remoto?"

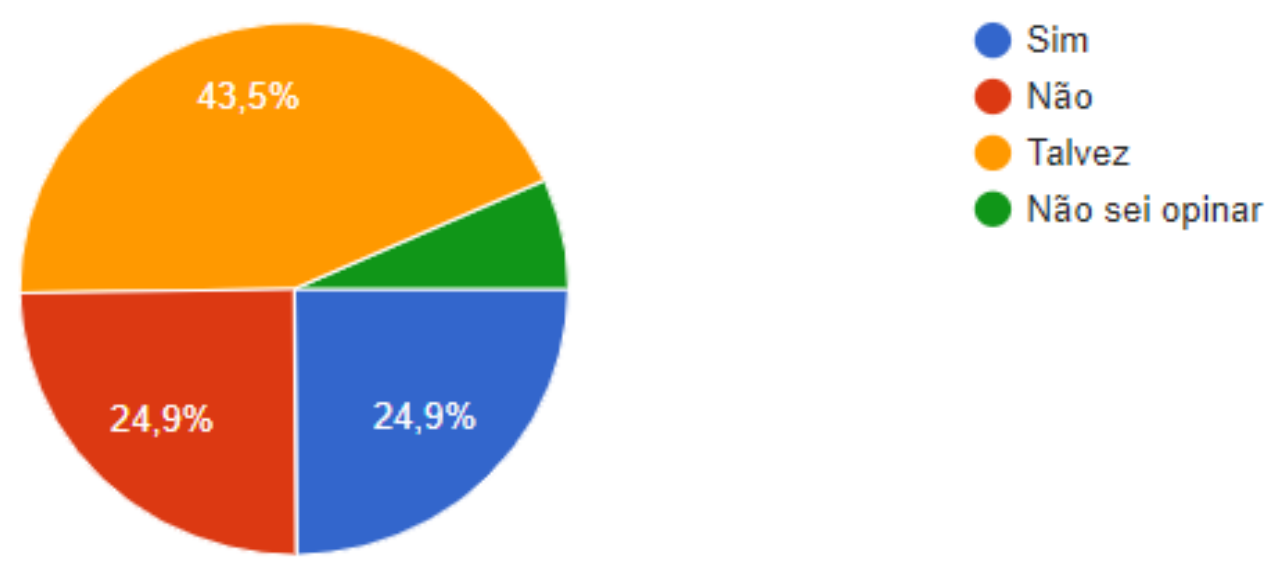

Fonte: Elaborado pelos autores (2020).

Sobre as ferramentas mais utilizadas no ensino remoto, o Google Meet (64\%) e WhatsApp (67\%) foram as mais citadas entre os docentes participantes da pesquisa. Também é válido destacar que, no momento em que foram questionados sobre as diferentes ferramentas tecnológicas adicionais a serem utilizadas nas atividades remotas, a maioria informou que as tem buscado (82\%). 
O uso das TDICs, com vistas a suprir as necessidades impostas pela condição sanitária mencionada, foi inevitável. No entanto, a inserção dessas ferramentas veio unida a muitos sentimentos de incerteza, desafios e receios tanto por parte dos docentes quanto dos discentes.

Embora a maior parte dos brasileiros, representada por 98,6\%, tenha acesso à internet pelo celular (IBGE, 2019), o que poderia conferir aos docentes maior aproximação com as diferentes ferramentas de ensino e aprendizagem, a situação de ineficácia e impotência apresentada por esses profissionais demonstrou que a formação de professores para o uso das TDICs no cotidiano escolar é bastante falha, fato que foi demonstrado pelos resultados apresentados no presente estudo.

Para Rondini, Pedro e Duarte (2020, p. 19) dizem que:

\begin{abstract}
As mudanças no sistema educacional tiveram que ser realizadas rapidamente, de sorte que, de um dia para o outro, os professores precisaram transpor conteúdo e adaptar suas aulas presenciais para plataformas on-line com o emprego das Tecnologias Digitais da Informação e Comunicação (TDIC), sem preparação para isso, ou com preparação superficial, também em caráter emergencial. Cabe destacar que a incorporação das TDIC nas instituições escolares ainda é um entrave na realidade nacional; problemas de infraestrutura e de formação docente deficitária são variáveis importantes que interferem diretamente em uma utilização crítica, intencional e produtiva das tecnologias.
\end{abstract}

Portanto, assim como antes, a pandemia da Covid-19 trouxe inúmeras reflexões no tocante ao modelo educacional vigente, que teve de ser adaptado a esta nova realidade (temporária ou não). Essas considerações estão ligadas, por exemplo, às condições de trabalho dos professores, à qualidade do processo de ensino e aprendizagem, à contextualização e relevância dos temas a serem trabalhados, bem como às ferramentas e práticas pedagógicas que serão utilizadas. Contudo, para tanto, há a necessidade de tempo para adaptação e preparo, a fim de que não haja precarização do ensino.

Antes do advento do ensino remoto, já havia uma discussão sobre o uso das tecnologias em sala de aula de forma crítica, e não apenas operacional, como evidência Tezani (2017, p. 305):

Desta forma, acreditamos que a educação escolar necessita rever seu papel diante das TDIC como instrumentos culturais da sociedade contemporânea, utilizando-as de modo crítico e consciente, de modo que as TDIC não sejam concebidas como salvadoras das mazelas da educação, mas como possibilidade de contribuir para o ensinar e para o aprender.

Os docentes pesquisados que atuavam apenas na modalidade presencial, que correspondem a $86,8 \%$, foram surpreendidos com o ensino remoto. Revelando dificuldades em sua adaptação ao uso das tecnologias, aquelas seriam facilmente superadas se houvesse momentos, anteriores à pandemia da Covid-19, de formações continuadas com 
esses professores acerca das ferramentas tecnológicas disponíveis. Para Tezani (2017, p. 296), "nossos alunos estão imersos no contexto digital. Inseridos em uma sociedade digitalizada na qual as TDIC estão presentes na organização e no funcionamento da vida cotidiana [...]."

Para Bacich e Moran (2018, p. 150) dizem que:

A formação de professores é considerada chave para a melhoria das escolas e para uma produtiva reforma curricular. Porém, muitas vezes, a proposta de formação é ineficiente, ao desconsiderar a lacuna entre o que os professores estudam e o contexto em que esse conhecimento é aplicado.

Ainda para os autores supracitados, a formação continuada de professores para o uso das tecnologias digitais deve ser feita por meio das mesmas. Nas palavras deles: "deixe, então, de aprender sobre o uso das tecnologias digitais para passar a aprender com o uso delas." (BACICH; MORAN, 2018, p. 150).

Logo, os momentos de formação continuada, nos quais há trocas de experiências entre os professores, são de vital importância para a melhoria do desempenho docente.

\section{CONSIDERAÇÕES FINAIS}

Dados numéricos que corroboraram as informações obtidas com o auxílio de observações empíricas e entrevistas foram de grande relevância para comprovar o que tem sido constantemente debatido, como é o caso das jornadas extenuantes em que os docentes estão ao longo dessa modalidade emergencial de ensino.

O presente estudo permitiu destacar que, além da sobrecarga de trabalho, boa parte dos docentes pesquisados não recebeu formações adequadas a respeito das plataformas digitais utilizadas em suas aulas remotas, e grande parte não foi orientada quanto ao uso de ferramentas tecnológicas adicionais para a aplicação no ensino remoto.

Logicamente, em tempos de isolamento social e pandemia, alternativas aos métodos tradicionais de educação e ensino são necessárias. No entanto, também é necessário que essas ações estejam bem planejadas e que seus atores principais estejam a par das ferramentas necessárias para a sua implementação.

De acordo com Valente et al. (2020, p. 23) diz que:

Toda a comunidade acadêmica está sendo severamente impactada e busca-se formas de lidar com a crise atual e realizar adequações no ensino. Nesse sentido, o Ensino Remoto Emergencial ganhou protagonismo em um momento de crise, colocando os docentes frente aos desafios de construir novas formas de ensinaraprender, ressignificando suas práticas pedagógicas. O trabalho do docente é apenas uma gota no mar de desafios que se impõem sobre a educação, especialmente no que se refere à redução de desigualdades de oportunidades de inclusão. 
É importante ressaltar que, mesmo com o fim da pandemia, essas questões deverão continuar sendo levadas ao debate, uma vez que a sobrecarga profissional do docente e as suas condições de trabalho, tanto em ambiente doméstico quanto escolar, possivelmente, permanecerão as mesmas.

Por fim, Saviani e Galvão (2021, p. 42) afirmam que:

No "ensino" remoto, ficamos com pouco ensino, pouca aprendizagem, pouco conteúdo, pouca carga horária, pouco diálogo. Em contrapartida, temos muitas tarefas. Do lado dos alunos, estes supostamente passam a ser "autônomos" e vão em busca do próprio conhecimento, assoberbados com a multiplicação de leituras, vídeos, podcasts, webinários etc.

Posto isso, este artigo visou alertar as comunidades docentes, discentes, políticas e comunitárias no que concerne à sobrecarga de trabalho dos professores, relatada outrora, em pesquisas diversas, todavia enfatizada em tempos de pandemia, e acerca da precariedade de formação continuada, a qual é fundamental, sobretudo, para a atuação e para as modalidades de ensino que demandam conhecimentos profundos.

\section{REFERÊNCIAS}

ALMEIDA, Tharcila de Abreu et al. Criatividade e Tecnologias Digitais na Educação em Tempos de Pandemia. Revista Carioca de Ciência, Rio de Janeiro, v. 6, n. 1, p. 66-78, 2021.

ALVES, Giovana Santos; FARIAS, Fabiane Moreira. A Síndrome de Burnout em tempos de estudo remoto. Revista do Salão Internacional de Ensino, Pesquisa e Extensão, v. 12, n. 2, 4 dez. 2020. Disponível em: https://periodicos.unipampa. edu.br/index.php/SIEPE/article/view/107131. Acesso em: 10 set. 2021.

ASSESSORIA de imprensa. Saiba como as escolas estão desenvolvendo as atividades domiciliares: professores estão seguindo seu planejamento a partir de uma nova lógica de trabalho. SINEPE/RS, Porto Alegre, 6 abr. 2020. Disponível em: https:// www.sinepe-rs.org.br/noticias/saiba-como-as-escolas-estao-desenvolvendo-as-atividadesdomiciliares. Acesso em: 27 ago. 2020.

BACICH, Lilian; MORAN, José. Metodologias ativas para uma educação inovadora: uma abordagem teórico-prática. São Paulo: Penso Editora, 2018.

BRASIL. Ministério da Educação. Gabinete do Ministro. Portaria n. 343, de 17 de março de 2020. Dispõe sobre a substituição das aulas presenciais por aulas em meios digitais enquanto durar a situação de pandemia do Novo Coronavírus - COVID-19. Diário Oficial da União: Seção 1, Brasília, DF, ed. 53, 18 mar. 2020. 
BROUWERS, A.; TOMIC, W.; BOLUIJT, H. Job demands, job control, social support and selfefficacy beliefs as determinants of burnout among physical education teachers. Europe's Journal of Psychology, n. 1, p.17-39, 2011.

CAMÉLO, Bruno de Carvalho. Burnout no ensino superior [manuscrito]: um estudo no contexto da pandemia do COVID-19. 2021. Trabalho de Conclusão de Curso (Bacharelado em Ciências Sociais Aplicadas) - Universidade Federal de Ouro Preto, Mines Gerais, 2021. 24 p.

CONSENTINO, G. C. Educadoras em tempos de pandemia: uma breve análise. In: CONGRESSO NACIONAL UNIVERSIDADE. Ead e Software Livre, v.2, n.12. 2021. Disponível em: https://nasnuv.com/ojs2/index.php/UEADSL/article/view/606. Acesso em: 10 set. 2021.

DALCIN, L.; CARLOTTO, M. S. Síndrome de Burnout em professores no Brasil: considerações para uma agenda de pesquisa. Psicologia em Revista, São Paulo, v. 23, n. 2, p. 745-771, 2017.

DIEHL, L.; CARLOTTO, M. S. Burnout Syndrome in teachers: differences in education levels. Research, Society and Development, [S. I.], v. 9, n. 5, p. 10-29, 2020. Disponível em: https://rsdjournal.org/index.php/rsd/article/view/2623. Acesso em: 26 out. 2020.

FUNDO DAS NAÇÕES UNIDAS PARA A INFÂNCIA - UNICEF. Covid-19: Mais de 95\% das crianças estão fora da escola na América Latina e no Caribe, estima o UNICEF. Publicado em 23 mar. 2020. Disponível em: https://www.unicef.org/brazil/ comunicados-de-imprensa/covid-19-mais-de-95-por-cento-das-criancas-fora-da-escolana-america-latina-e-caribe. Acesso em: 17 set. 2021.

GOMES, Vânia Thais Silva et al. A Pandemia da Covid-19: repercussões do ensino remoto na formação Médica. Revista Brasileira de Educação Médica. Brasília, DF, v. 44, n. 4, jan., 2020. Disponível em: https://doi.org/10.1590/1981-5271v44.4-20200258. Acesso em: 26 out. 2021.

INSTITUTO BRASILEIRO DE GEOGRAFIA E ESTATÍSTICA - IBGE. Uso de internet, televisão e celular no Brasil. 2019. Disponível em: https://educa.ibge.

gov.br/jovens/materias-especiais/20787-uso-de-internet-televisao-e-celular-no-brasil.html. Acesso em: 26 out. 2021.

JASKIW, E. F. B.; LOPES, C. V. G. A pandemia, as TDIC e ensino remoto na educação básica: desafios para as mulheres que são mães e professoras. SCIAS - Educação, Comunicação E Tecnologia, São Paulo, v. 2, n. 2, p. 231-250. 2021. Disponível em:https://doi.org/10.36704/sciaseducomtec.v2i2.5033. Acesso em: 10 set. 2021.

KRAVISKI, Mariane Regina. Formar-se para formar: formação continuada de professores da educação superior em serviço - em metodologias ativas e ensino híbrido. 
2019. Dissertação (Mestrado em Profissional em Educação e Novas Tecnologias) - Centro Universitário Internacional - UNINTER. Curitiba, 2019. 130 pg. Disponível em: https:// repositorio.uninter.com/handle/1/332. Acesso em: 10 set. 2021.

LIBANEO, José Carlos. Buscando a qualidade social do ensino. In: LIBANEO, José Carlos. Organização e Gestão da Escola: teoria e prática. Goiânia: Editora Alternativa, 2001.

MENTAL HEALTH FOUNDATION. Stress [Internet]. 2021. Disponível em: https://www. mentalhealth.org.uk/a-to-z/s/stress. Acesso em: 26 out. 2021.

NURHIDAYATI, T.; RAHAYU, D. A.; ALFIYANTI, D. Nursing students' coping for burnout and fatigue online learning during coronavirus disease 2019 pandemic. Open Access Maced J Med Sci. v. 9, n. 4, p. 92-96, 2021.

ORGANIZAÇÃO MUNDIAL DA SAÚDE - OMS. Coronavirus disease (COVID-19) situation report-102. (2020). Disponivel em: https://www.who.int/docs/default-source/ coronaviruse/situation-reports/20200501-covid-19-sitrep.pdf?sfvrsn= 742f4a18_2. Acesso em: 10 set. 2021.

RONDINI, C. A; Pedro, K. M; Duarte, C. dos S. Pandemia do COVID-19 e o ensino remoto emergencial: mudanças na práxis docente. Revista Educação, São Paulo, v. 10, n. 1, p. 41-57. 2020. Disponível em: https://doi.org/10.17564/2316-3828.2020v10n1p41-57. Acesso em: 10 set. 2021.

SARAIVA, K.; TRAVERSINI, C. LOCKMNN, C. A educação em tempos de COVID-19: ensino remoto e exaustão docente. Práxis Educativa, Ponta Grossa, v. 15, p. 1-24, 2020. Disponível em: https://doi.org/10.5212/PraxEduc.v.15.16289.094. Acesso em: 10 set. 2021.

SAVIANI, Demerval; GALVÃO, Ana Carolina. Educação na Pandemia: a falácia do "ensino" remoto. Revista da Universidade e Sociedade, Brasília, DF, n. 67, p. 36-49. jan., 2021. Disponível em: https://www.andes.org.br/img/ midias/0e74d85d3ea4a065b283db72641d4ada_1609774477.pdf. Acesso em: 10 ago. 2021.

SEVERINO, Antônio Joaquim. Metodologia do Trabalho da Pesquisa. 23. ed. São Paulo: Cortez, 2007.

TEZANI, Thais Cristina Rodrigues. Nativos Digitais: considerações sobre os alunos contemporâneos e a possibilidade de (re)pensar a prática pedagógica. DOXA Rev. Bras. Psicol. Educ., Araraquara, v. 19, n. 12, p. 295-307, jul./dez., 2017. Disponível em: https:// periodicos.fclar.unesp.br/doxa/article/view/10955. Acesso em: 15 set. 2021.

VAEZI, S.; FALLAH, N. The relationship between emotional intelligence and burnout among Iranian EFL teachers. Journal of Language Teaching and Research, v. 2, n. 5, p. 1122-1129, 2011. 
VALENTE, G. S. C.; MORAES, Érica B. de.; SANCHEZ, M. C. O..; SOUZA, D. F. de.; PACHECO, M. C. M. D. Remote teaching in the face of the demands of the pandemic context: reflections on teaching practice. Research, Society and Development, [S. I.], v. 9, n. 9, 2020. Disponível em: https://www.rsdjournal. org/index.php/rsd/article/view/8153. Acesso em: 26 nov. 2021.

WOLD BANK GROUP. Políticas Educacionais na Pandemia a Covid-19: o que o Brasil pode aprender com o resto do mundo? Publicado em 2 abr. 2020. Disponível em: http://pubdocs.worldbank.org/en/413781585870205922/pdf/ POLITICAS-EDUCACIONAIS-NA-PANDEMIA-DA-COVID-19-O-QUE-O-BRASIL-PODEAPRENDER-COM-O-RESTO-DO-MUNDO.pdf. Acesso em: 26 set. 2020.

YOUTUBE UNIVATES. Diálogos na Pandemia: educação em tempos de pandemia. Youtube, Publicado em 01 jun. 2020. Disponível em: https://www.youtube.com/ watch?v=myPm-hU39lw\&feature=youtu.be. Acesso em: 26 set. 2020 .

Recebido em 05 de outubro de 2021 Aprovado em 26 de novembro de 2021 